\title{
USO DA SUBMUCOSA INTESTINAL PORCINA CONSERVADA EM SULFATO DE NEOMICINA NA ENXERTIA ESOFÁGICA EM CÃO
}

\author{
(Use of porcine intestinal submucous conserved in neomycin sulphate \\ in esophagus graft in dog)
}

\author{
VILLANOVA JR., J.A. ${ }^{1}$; DALECK, C.R. ${ }^{2}$; WOUK, A.F.P.F. ${ }^{3}$; CIRIO, S.M. ${ }^{1}$
}

${ }^{1}$ Pontifícia Universidade Católica do Paraná; ${ }^{2}$ Universidade Estadual Paulista. Campus Jaboticabal; ${ }^{3}$ Universidade Federal do Paraná e Pontifícia Universidade Católica do Paraná.

\begin{abstract}
RESUMO - Verificou-se a eficácia da submucosa intestinal porcina como alternativa para substituir três centímetros de esôfago cervical em cão, e o uso de sulfato de neomicina como meio de conservação desta membrana biológica. Nestes estudos foram utilizados dezesseis cães adultos, sendo quatro avaliados durante sete dias, quatro durante 15 dias, quatro durante 30 dias e os restantes avaliados durante 45 dias de período pós-operatório. A avaliação pós-operatória constitui-se de exames clínicos e laboratoriais, e ao final do período de acompanhamento, foram submetidos à eutanásia para exame de necropsia e colheita da área enxertada para avaliação histopatológica. Este trabalho possibilitou concluir que o emprego desta membrana biológica na forma como foi conservada, permite a substituição de parte de esôfago cervical canino, proporcionando rápida e completa proliferação epitelial. Aárea de enxertia aos 30 dias do período pós-operatório mostrou-se ineficaz sob o ponto de vista funcional, nas medidas estudadas (substituição de três centímetros de esôfago cervical), pois ocorreram em todos os animais operados, estenoses e conseqüentemente engasgos, hiporexia, desnutrição e caquexia. Os autores consideram que o esôfago continua sendo um desafio cirúrgico.
\end{abstract}

Palavras-chave: anastomose esofágica; membrana biológica; enxerto; sulfato de neomicina; cirurgia.

\footnotetext{
ABSTRACT - It has been verified the effectiveness of the porcine intestinal submucous as an alternative to replace three centimeters of cervical esophagus in dog and the use of neomycin sulphate as a way for the conservation of this biological membrane. In these studies sixteen adult animals were used, four animals being evaluated for seven days, four for fifteen days, four for thirty days and the remaining four were observed for forty-five days after the surgery. The postoperative evaluation consists of clinical and laboratory examinations, and at the end of the post-operation followup period they were euthanized and underwent necropsy, the grafted area was harvested for a histopathological exam. This research made it possible to conclude that the use of a biological membrane, replacing part of the
}

canine cervical esophagus is an executable method as it allows a quick epithelial proliferation. The area of graft at the 30 days after the surgery period showed, to be not functionally effective in the studied proportions (substitution of three centimeters of cervical esophagus) displaying in all the operated animals, stenosis and consequently chokes, hypoxia, lack of nutrition and cachexia. The authors consider that the esophagus follows being a surgical challenge.

Key-words: esophagus anastomosis; biological membrane; graft; neomycin sulphate; surgery.

\section{Introdução}

Intervenções operatórias esofágicas requerem, provavelmente, mais habilidade e precisão do que qualquer outra porção do trato alimentar, pois o esôfago é mais propenso à deiscência pós-operatória. Os principais elementos implicados no aumento do risco relativo de extravasamento ou deiscência no esôfago são: ausência de revestimento seroso completo, ausência de omento e irrigação segmentar com áreas com baixo fluxo sangüíneo (PAVLETIC, 1996).

Segundo HEDLUNG (1997), tensão, movimentos constantes como resultado da deglutição e do movimento diafragmático, passagem de saliva e debilitação do paciente são elementos que implicam em complicações pós-operatórias. A formação de estenose, decorrente de cicatrização esofágica é uma complicação pós-operatória que merece grande consideração. Segundo DALECK et al (1988), lesões esofágicas menores que um quarto da circunferência esofágica e que tenham bordas de tecido viável, podem ser debridadas e suturadas. A falência da anastomose esofágica é mais provável, se a área ressecada for superior a dois centímetros de comprimento (TOBIAS, 1999). Nas lesões maiores, são necessários procedimentos alternativos para substituir segmentos esofágicos, porém, nem sempre os cirurgiões dispõem de técnicas satisfatórias para que haja conforto pósoperatório (ZILBERSTEIN et al., 1987).

A submucosa intestinal porcina é uma matriz 
Uso da submucosa intestinal porcina conservada em sulfato de neomicina na enxertia esofágica em cão

colágena extracelular que promove resistência ao reparo de tecidos, favorecendo sua regeneração sem ocorrer rejeição no cão, moldando-se, induzindo assim, a regeneração de tecido nativo no qual foi enxertada. Ela promove crescimento de vasos sangüíneos, participa de processos de diferenciação celular, consegue reconstruir a estrutura orgânica lesada por possuir em sua composição estrutural, fatores de crescimento (GRECA, 2001; SOUZA FILHO et al, 2005).

A estenose esofágica pós-operatória pode ser avaliada por radiografias contrastadas ou no exame post-mortem, com alginato injetado no esôfago (BORBA JúNIOR et al., 1998).

Objetivando testar a eficácia da submucosa intestinal porcina como alternativa para substituir três centímetros de esôfago cervical canino, e o uso de sulfato de neomicina como meio de conservação de membranas biológicas, realizou-se exérese parcial do órgão, seguida de enxertia da membrana biológica.

\section{Material e Métodos}

Foram utilizados 16 cães, machos e fêmeas adultos, sem raça definida, com peso entre oito e $14 \mathrm{Kg}$, submetidos a exames clínicos e laboratoriais. $\mathrm{Na}$ seqüência, foram eles alojados em canis individuais, por um período mínimo de 15 dias para adaptação, onde receberam alimentação e manejo adequados. Os animais foram separados em quatro grupos de igual número. $\mathrm{O}$ Grupo I foi avaliado até sete dias, o Grupo II até 15 dias, o Grupo III até 30 dias, enquanto que o Grupo IV foi avaliado até 45 dias de período pós-operatório.

A submucosa intestinal porcina foi obtida de um segmento de jejuno proximal, coletada em abatedouro. Em seguida, o material foi lavado com solução fisiológica e acondicionado em frascos contendo sulfato de neomicina a $10 \%$, onde permaneceu totalmente imerso, à temperatura de $4^{\circ} \mathrm{C}$, por período não inferior a 48hs, e não superior a 30 dias.

Para o período trans-operatório, os animais foram mantidos em jejum hídrico e alimentar de 12h. Trinta minutos antes das intervenções cirúrgicas, os cães foram submetidos à administração subcutânea, de ceftiofur sódico $(2 \mathrm{mg} / \mathrm{kg})$ mantida por mais cinco dias. Neste mesmo tempo que antecedia o procedimento cirúrgico era administrado $2 \mathrm{mg} / \mathrm{kg}$ de cetoprofeno e $1 \mathrm{mg} / \mathrm{kg}$ subcutâneo a cada $24 \mathrm{~h}$ durante mais quatro dias. A medicação pré-anestésica utilizada foi maleato de acepromazina $(0,1 \mathrm{mg} / \mathrm{kg})$, seguida da indução anestésica após $20 \mathrm{~min}$ com tiopental sódico na dose média de $12,5 \mathrm{mg} / \mathrm{kg}$, ambos por via intravenosa. A manutenção anestésica foi feita com halotano diluído em oxigênio.

A submucosa intestinal porcina foi retirada do estado de refrigeração, dez minutos antes da enxertia, para a lavagem e retirada do conservante excedente; para isso utilizou-se uma cuba estéril contendo solução fisiológica em temperatura ambiente. Após remoção de três centímetros de esôfago cervical dos animais, foi colocado o enxerto de mesmo tamanho. O fio de sutura utilizado para a síntese do esôfago e da submucosa intestinal porcina foi poliglactina 910, nํ3-0, em técnica de pontos isolados simples. As suturas envolviam $3 \mathrm{~mm}$ das bordas tanto do esôfago como da membrana biológica utilizada, e estavam eqüidistantes de $2-3 \mathrm{~mm}$ entre si. A síntese das demais camadas foi realizada de maneira rotineira.

O jejum foi mantido por 24 h após a operação e durante este período, os animais receberam fluidoterapia com solução de Ringer com lactato, na dose de $100 \mathrm{ml} / \mathrm{kg} / \mathrm{dia}$, dividida em duas vezes ao dia, sendo que para cada $500 \mathrm{ml}$ desta solução, foi adicionada uma ampola de $20 \mathrm{ml}$ de glicose a $50 \%$. Após este período, passaram a receber dieta líquida à base de leite e ração comercial, passando gradativamente para dieta pastosa, com água ad libitum.

Foram feitos exames clínicos diários, com ênfase no comportamento após a alimentação, padrão respiratório e temperatura retal, além da realização de análises hematológicas (hemograma, creatinina, uréia e alanino amino transferase).

Para análise histológica da área enxertada, os animais foram submetidos à eutanásia, com maleato de acepromazina, tiopental sódico e cloreto de potássio. À necropsia, o enxerto foi analisado quanto à presença de aderências, fístulas, deiscências e estreitamento do diâmetro esofágico. O esôfago foi isolado numa extensão de $10 \mathrm{~cm}$, sendo seccionadas suas extremidades e em seguida posto em gaze embebida com solução fisiológica a $0,9 \%$. Com o material de estudo em superfície rígida na posição horizontal, procedeu-se à moldagem intra-esofágica, com solução hidrocolóide irreversível, de Alginato. O parâmetro para esta análise foi a medição $(\mathrm{em} \mathrm{cm})$ do diâmetro do molde do esôfago, no local da aplicação do enxerto, mais o valor do diâmetro medido distando do estoma anastomótico esofágico, $2 \mathrm{~cm}$ no sentido cranial e $2 \mathrm{~cm}$ no sentido caudal. Os valores encontrados foram aplicados na fórmula para determinação do índice de estenose, descrita por McADAMS et al. (1970), que consiste no seguinte:

$$
\text { Índice de estenose }=100\left(1-\frac{2 A}{B+C}\right)
$$

$\mathrm{A}=$ diâmetro no local do reparo; $\mathrm{B}=$ diâmetro distante $2 \mathrm{~cm}$, cranialmente ao reparo, e $\mathrm{C}=$ diâmetro distante $2 \mathrm{~cm}$, caudalmente ao reparo. 
O índice de estenose zero corresponde à ausência de estenose e o índice 100 é indicativo de estenose completa.

Após aferição do grau de estenose, a área de enxertia foi imersa em solução fixadora de Bouin, seguida de formol a $10 \%$ e os fragmentos retirados da região operada foram inclusos em parafina, cortados em micrótomo, corados pelos métodos de Hematoxina-Eosina, Tricrômico de Mallory, Tricrômico de Shorr e Azul de Toluidina e analisados em microscopia ótica.

\section{Resultados e Discussão}

Os 16 cães submetidos à enxertia apresentaram leucocitose, sendo predominante a neutrofilia. A normalidade foi restabelecida após duas semanas de período pós-operatório; e as provas bioquímicas não demonstraram alterações significativas após este período. Indistintamente, houve má adaptação à alimentação, sendo observados engasgos, hiporexia, regurgitação, disfagia, além de perda de peso e apatia. O início destas complicações ocorreu entre $07^{\circ}$ e $012^{\circ}$ dia de período pós-operatório. Em apenas um dos animais do grupo de 30 dias de avaliação pós-operatória não houve significativa perda de peso, e a recuperação foi gradativamente melhorada, com esporádicos episódios de regurgitação. Especificamente este animal adotou o hábito de ingerir pequenos volumes de alimento, com menor intervalo de tempo entre as refeições, compensando assim, uma eventual desnutrição. Os animais pertencentes aos grupos de 30 e 45 dias de avaliação pós-operatória, estavam caquéticos ao término das avaliações clínicas, momento este que antecedia a eutanásia. Em todos os animais ocorreram aderência muscular, e nítido estreitamento do diâmetro esofágico. Observou-se presença de fístulas, com áreas de necroses em dois animais, e nos outros 14 tais achados de necropsia não foram observados, visualizando-se áreas de estenose esofágica (FIGURA 1) e epitelização da mucosa.

\section{FIGURA 1 - ESÔFAGO CERVICAL CANINO APÓS 30 DIAS DA ENXERTIA DE SUBMUCOSA INTESTINAL PORCINA. OBSERVAR ESTENOSE ESOFÁGICA (SETA MAIOR) EVIDENCIADA PELO MOLDE DE ALGINATO (SETA MENOR).}

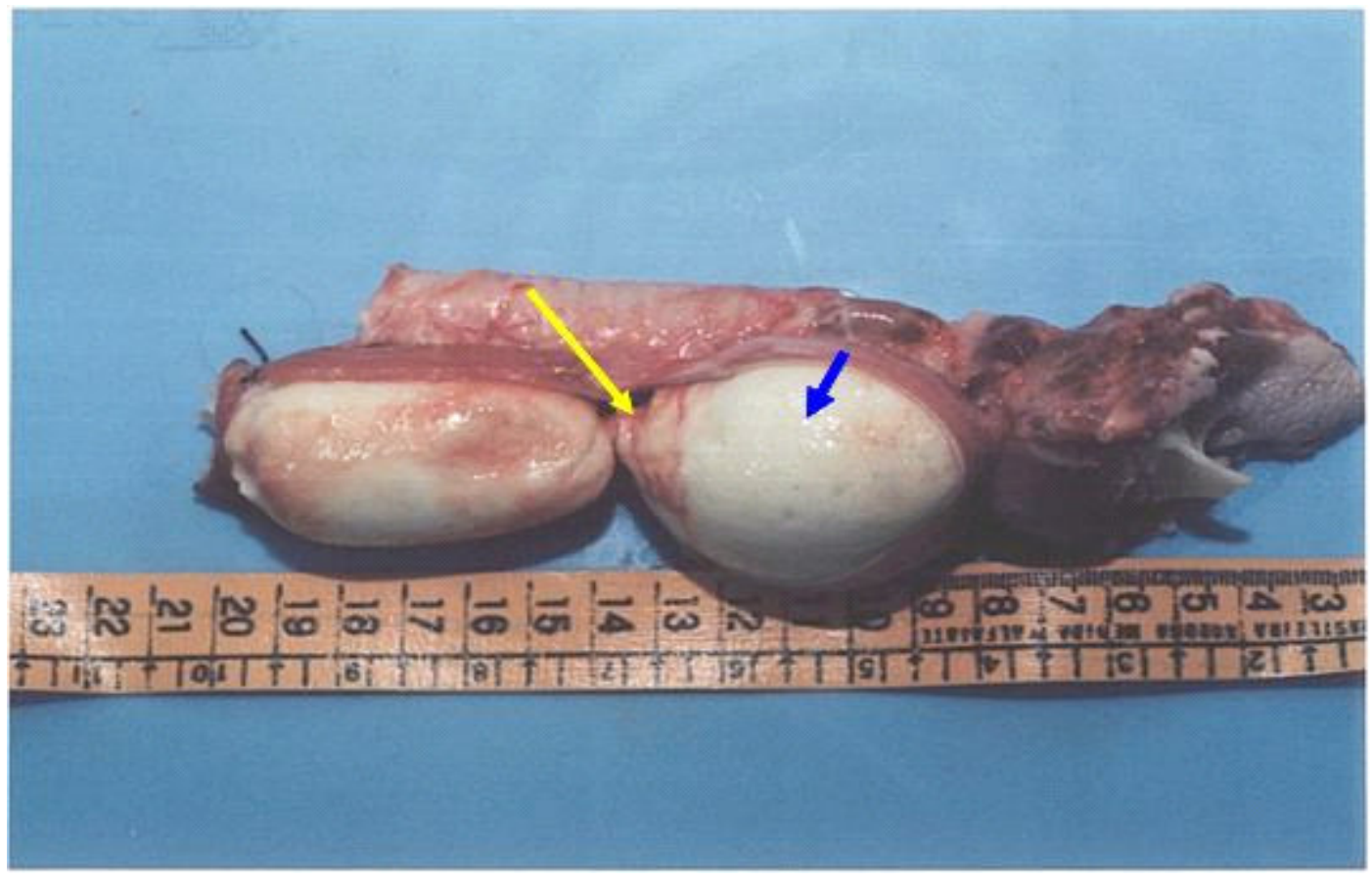


Uso da submucosa intestinal porcina conservada em sulfato de neomicina na enxertia esofágica em cão

O exame histopatológico do esôfago, sete dias após o enxerto revelou perda epitelial com regeneração nas bordas da lesão. Nesta área havia severa reação inflamatória. A submucosa porcina se apresentava como material amorfo envolvido e infiltrado por leucócitos, predominando neutrófilos. Também se observou tecido de granulação jovem, e cortes do fio de sutura estavam envoltos por células gigantes multinucleadas tipo corpo estranho, neutrófilos, macrófagos e mastócitos. As glândulas mucosas eram ausentes e as fibras musculares estriadas na área de transição estavam tumefactas eosinofílicas, sem estriações transversais e multinucleadas (FIGURA 2).

FIGURA 2 - FOTOMICROGRAFIA DA ÁREA OPERATÓRIA DO ESÔFAGO DE CÃES, SETE DIAS APÓS ENXERTIA. NOTA-SE PROLIFERAÇÃO DE FIBROBLASTOS (SETAS MAIORES) E NEOVASCULARIZAÇÃO (SETAS MENORES). TRICRÔMICO DE SHORR. OBJ. 40X.

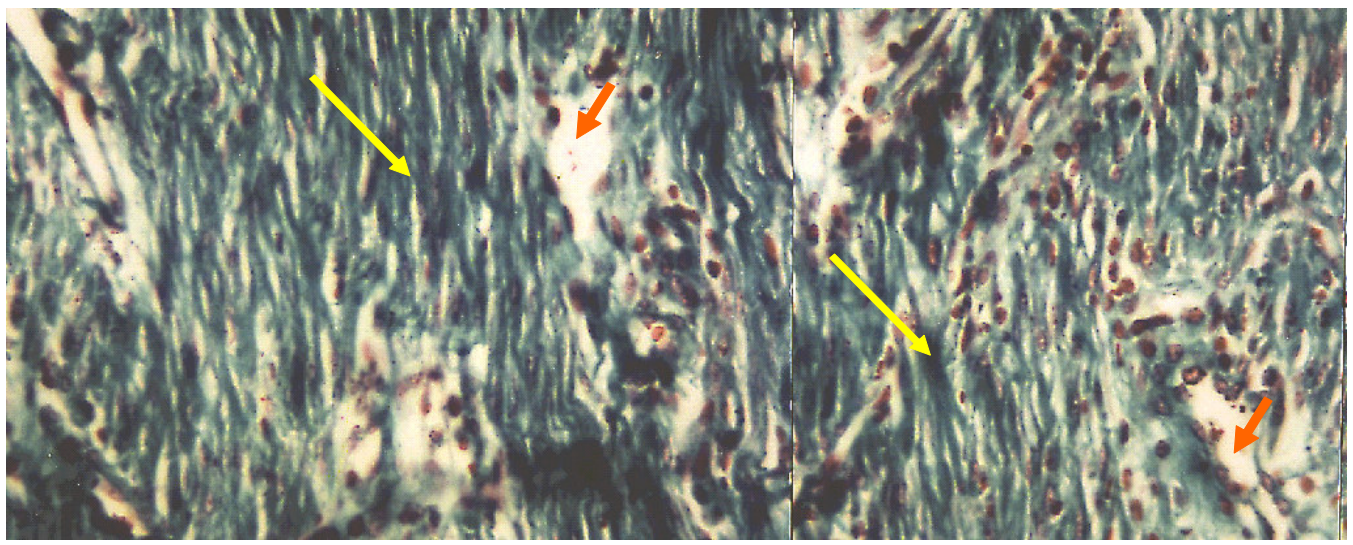

Após 15 dias de pós-operatório, na área desprovida de epitélio, predominavam células monomorfonucleares e havia remanescentes da membrana enxertada. O tecido de granulação estava maturo e na região de transição, as fibras musculares estriadas apresentavam sinais de regeneração com presença de numerosos núcleos. Aos
30 dias, o epitélio apresentava-se regenerado e o tecido cicatricial era denso com numerosas fibras colágenas e pouca vascularização. As fibras musculares eram alongadas, algumas multinucleadas e com estriações transversais (FIGURA 3). Após 45 dias, observou-se apenas regressão vascular.

\section{FIGURA 3 - FOTOMICROGRAFIA DO ESÔFAGO DE CÃO, DA ÁREA OPERATÓRIA 30 DIAS APÓS A ENXERTIA. NOTA-SE REEPITELIZAÇÃO COMPLETA (SETAS MENORES) E A REGENERAÇÃO DE FIBRAS MUSCULARES ESQUELÉTICAS (SETAS MAIORES). TRICRÔMICO DE SHORR. OBJ. DE 4X.}

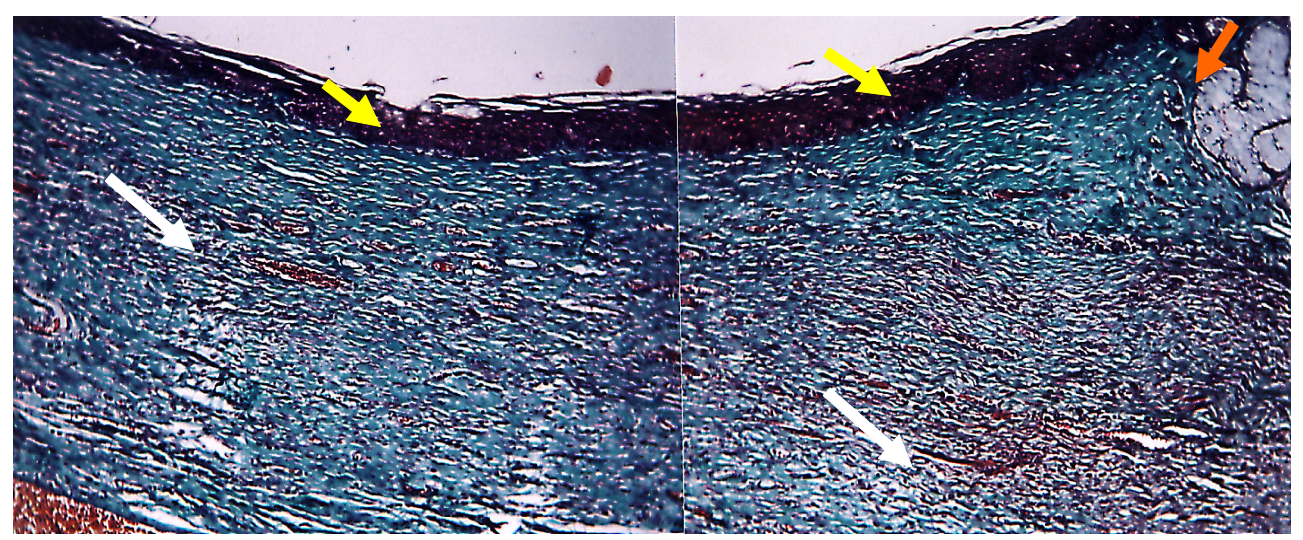


VILLANOVA JR., J.A. et al.

O período de jejum utilizado foi em média de $18 \mathrm{~h}$, na tentativa de se evitar ocorrências de deiscências dos pontos de sutura, regurgitação e contaminação do campo operatório. Nas intervenções cirúrgicas esofágicas, a utilização de antibióticos parece não ser de fundamental importância, como mostra SOUZA FILHO et al (2004; 2005) em seus estudos, optando pela não utilização de antibióticos ou no uso em dose única, no momento da indução anestésica, usando por via intravenosa, cefazolina 500mg para cães que tinham média de peso de 15 quilogramas, obtendo taxas de fistulação e infecção iguais a zero com ou sem o uso de antibióticos. Neste estudo, optou-se pela utilização de ceftiofur sódico, na dose de $2 \mathrm{mg} / \mathrm{kg}$ corporal, por via subcutânea, a cada $24 \mathrm{~h}$, durante cinco dias, e do total de 16 cães operados, em dois deles (12,5\%), ocorreram infecções relacionadas ao ato operatório.

O sulfato de neomicina a 10\% mostrou-se satisfatório em relação à eliminação de bactérias pertinentes à área de enxertia, assim como já descrevia GRECA et al (2004a; 2004b; 2005) e SOUZA FILHO et al (2004; 2005).

Neste estudo pode-se comprovar diversas vantagens do uso de submucosa de intestino delgado porcino como substituto esofágico, destacando-se: 1) maior adequação de calibre entre esta membrana e o esôfago; 2) por ser a mais resistente à tensão; 3) ser a flora bacteriana do intestino delgado em menor número que a do intestino grosso; 4) facilidade da obtenção da membrana biológica em abatedouros; 5) por ser a submucosa de intestino delgado possuidora de baixa antigenicidade, graças a sua constituição de matriz extracelular; 6) a submucosa intestinal porcina permite o crescimento de vasos sangüíneos, participando de processos de diferenciação celular e resistindo ao desenvolvimento de agentes infecciosos.

A metodologia utilizada nesse estudo para aferir o índice de estenose foi bastante eficaz, como demonstrado por McADAMS et al. (1970), revelando nesta pesquisa, níveis de estenose próximos a $100 \%$.

$O$ fio de sutura empregado, poliglactina 910 n 3-0, mostrou-se resistente e de fácil manuseio. A sutura foi facilitada por ser esta membrana biológica uma estrutura tubular. A sutura isolada conferiu facilidade na confecção e boa resistência à região, sendo que a membrana manteve-se adequada e suficientemente elástica, resultados também obtidos por SOUZA FILHO et al. $(2004 ; 2005)$ quando optou por sutura contínua simples e uso de poliglecaprone 25 (Monocryl®) n.4-0.

À necropsia, a membrana biológica enxertada apresentava-se de coloração normal, sem sinais microscópicos de necrose e isquemia, mas com visível estenose em graus elevados. Dois animais apresentaram pequenas fístulas cervicais que apareceram no $7^{\circ}$ e no $9^{\circ}$ dias de pós-operatório. As porcentagens dos achados e sinais clínicos vistos no período pós-operatório tardio, estão presentes na TABELA 1.

TABELA 1 - ACHADOS E SINAIS CLÍNICOS VISTOS NO PERÍODO PÓS-OPERATÓRIO TARDIO.

\begin{tabular}{lc}
\multicolumn{1}{c}{ SINAIS CLÍNICOS } & PORCENTAGEM (\%) \\
\hline ENGASGOS & 100 \\
HIPOREXIA & 93,75 \\
REGURGITAÇÃO & 100 \\
DISFAGIA & 100 \\
PERDA DE PESO & 93,75 \\
APATIA & 100 \\
DESNUTRIÇÃO & 93,75 \\
PRESENÇA DE FÍSTULAS & 12,50 \\
ESTENOSE ESOFÁGICA & 100 \\
\hline
\end{tabular}

Descobrir e identificar fatores relevantes à cicatrização esofágica foi o maior intuito deste trabalho, bem como o emprego de submucosa intestinal porcina, como membrana biológica para anastomose esofágica, diante de um desafio cirúrgico. Além destes fatores já citados, avaliouse a possibilidade do uso de sulfato de neomicina como meio de conservação deste biomaterial, com a sua utilização com período bastante curto, tratamento nesta solução antimicrobiana por apenas 48 horas.

\section{Conclusões}

Frente aos resultados obtidos pode-se concluir que: a submucosa intestinal porcina serviu no plano experimental como substrato, podendo tornar-se uma alternativa viável na reconstrução esofágica de cães; o sulfato de neomicina mostrou-se eficiente como meio de conservação da submucosa intestinal porcina e sugere-se que as intervenções cirúrgicas com uso de submucosa intestinal porcina sejam complementadas com outras intervenções.

\section{Referências}

BORBA JÚNIOR, C.V.; NIGRO, A.J.T.; GOMES, P.O.; FRANCISCO NETO, A. Enxerto de fáscia lata autógena em ferimentos penetrantes provocados no esôfago cervical em cães. Acta Cirúrgica Brasileira, v. 13, n.3, p. $184-193,1998$. 
Uso da submucosa intestinal porcina conservada em sulfato de neomicina na enxertia esofágica em cão

DALECK, C.R.; DALECK, C.L.M.; GANDOLFI, W. Esofagoplastia cervical no cão com peritônio autólogo ou homólogo - "estudo experimental". Ciência Veterinária, v. 2, n. 1, p. 1-2, 1988.

GRECA, F.H. Utilização da submucosa de intestino delgado porcino como retalho para aumento da capacidade da bexiga "Estudo experimental em cães”. X Seminário de Iniciação Científica e IX Amostra de Pesquisa da PUCPR - Caderno de Resumos, Ed. Universitária Champagnat, Curitiba, p. 107, 2001.

GRECA, F.H.; SOUZA FILHO, Z.A.; ROCHA S.L.; BORSATO, K.S.; FERNANDES, H.A.D.; NIISIDE, M.A. Submucosa de intestino delgado no reparo de defeito em parede abdominal de ratos. Acta Cirúrgica Brasileira, v. 19, n. 5, p. 471-477, 2004a.

GRECA, F.H.; SOUZA FILHO, Z.A.; SILVA, A.P.G.; LEONEL, I.S.; SOCCOL, A.T.; FERES, A.N.; LONGHI, P.S. E. Utilização da submucosa de intestino delgado porcino como retalho para aumento da capacidade vesical em cães. Acta Cirúrgica Brasileira, v.19 n.6, p. $670-676,2004 b$.

GRECA, F.H.; NORONHA, L.; COSTA, F.D.A.; SOUZA FILHO, Z.A.; SOCCOL, A.T.; FERES, A.N.; DUDA, J.R.; ADAMS E. Estudo comparativo da biocompatibilidade da submucosa intestinal porcina e pericárdio bovino usados como enxertos na veia cava de cães. Acta Cirúrgica Brasileira, v. 20, n.4, p. 317-322, 2005.

HEDLUNG, C.S. Surgery of esophagus. In: FOSSUM, T.W. Small Animal Surgery. St. Louis: Mosby, p. 232250, 1997.
McADAMS, A.J.; MEIKLE, A.G.; TAYLOR, J. O. One layer or two layer colonic anastomosis? The American Journal of Surgery, v.120, p.546-50, 1970.

PAVLETIC, M.M. Esôfago (Técnicas de reconstrução esofágica). In: BOJRAB, M. J. Técnicas Atuais em Cirurgia de Pequenos Animais. $3^{\text {a }}$ ed., Roca; São Paulo, 1996. p. 192-203.

SOUZA FILHO, Z.A.; GRECA, F.H.; DUDA, J.R.; CRAVO, G.Z.; IOSHII, S.O. Emprego da submucosa de intestino delgado na correção de estenose esofágica em cães. Acta Cirúrgica Brasileira, v.19, n.4, p. 415430, 2004.

SOUZA FILHO, Z.A.; GRECA, ROCHA, S.L.; IOSHII, S.O.; DOMANSKI, A.C.; KFOURI, D.; CAMPOS, P.D.P.; SILVA, R.F.K.C. Enxerto de submucosa porcina no tratamento de lesões duodenais em cães. Acta Cirúrgica Brasileira, v. 20 , n.5, p. 394398, 2005.

TOBIAS, K.S. Sistema Alimentar. In: HARARI, J. Cirurgia de Pequenos Animais, Porto Alegre: Ed. Artes Médicas do Sul Ltda., p. 148-180, 1999.

ZILBERSTEIN, B.; NASI, A; PINHEIRO, E.A., POLLARA, W.M ; CECCONELLO, I.; BRANDÃO, L.; LEÃO, P.P.; FERRAZ, A.R.; PINOTTI, H.W. Autotransplante do intestino delgado em substituição ao esôfago cervical. Indicação, técnica e experiência clínica. Revista do Hospital de Clínicas da Faculdade de Medicina de São Paulo, v.42, n.1, p.21-25, 1987.

Recebido para publicação:

$31 / 03 / 2006$

Aprovado: 